www.volsu.ru

DOI: https://doi.org/10.15688/jvolsu11.2017.4.6

UDC 504.064.2

LBC 20.18

\title{
ASSESSMENT OF THE ACTUAL STATE OF GREEN PLANTINGS IN SANITARY PROTECTION ZONE OF SMELTER VMK «KRASNY OKTYABR» CJSC, VOLGOGRAD ${ }^{1}$
}

\author{
Anna A. Tikhonova \\ Volgograd State University, Volgograd, Russian Federation \\ Dmitriy A. Shkolnykh \\ Volgograd State University, Volgograd, Russian Federation
}

\begin{abstract}
This work is devoted to the assessment of the actual state of tree plantation in smelter's sanitary protection zone by means of vision estimate of plant health. The research subject is the forest plantation in sanitary protection zone of steel plant VMK «Krasny Oktyabr» CJSC, Volgograd. The research was conducted at the end of the growing season in 2017 from the end of September to mid-October. We divided survey plot into 7 pre-selected geobotanical sites with an area of $400 \mathrm{~m}^{2}$. According to the received data, the species composition is dominated by Ulmus pumila and Fraxinus pennsylvanica, occupying $77 \%$. Populus pyramidalis and Robinia pseudoacacia have the best state of health; Fraxinus pennsylvanica, Morus nigra and Ulmus pumila by contrast have the worst state. For information, $43 \%$ of the trees were classified as damaged and $40 \%$ were strongly damaged. Based on this analysis we concluded that it indicates heavy environmental contamination from metallurgic plant combining with harsh climatic conditions and lack of forest's tending. This situation leads to reducing the defense characteristics of sanitary protection zone and, thus, the negative impact of VMK « Krasny Oktyabr » on the surrounding area, including settlement zone, will be increased.
\end{abstract}

Key words: sanitary protection zone, plant health, metallurgic plant, environmental monitoring.

УДК 504.064.2

ББК 20.18

\section{ОЦЕНКА ФАКТИЧЕСКОГО СОСТОЯНИЯ ЗЕЛЕНЫХ НАСАЖДЕНИЙ САНИТАРНО-ЗАЩИТНОЙ ЗОНЫ АО ВМК «КРАСНЫЙ ОКТЯБРЬ» Г. ВОЛГОГРАДА ${ }^{1}$}

\footnotetext{
Анна Афанасьевна Тихонова

\author{
Волгоградский государственный университет, г. Волгоград, Российская Федерация \\ Дмитрий Александрович Школьных
}

Волгоградский государственный университет, г. Волгоград, Российская Федерация \begin{abstract}
состояния древесных насаждений санитарно-защитной зоны предприятия черной металлургии. В качестве объекта исследования была выбрана санитарно-защитная зона АО ВМК «Красный октябрь» г. Волгограда. Исследование проводилось в конце вегетационного периода 2017 года (3 декада сентября - 2 декада октября) натурным методом на предварительно выбранных геоботанических площадках площадью 400 м². Согласно полученным данным, в породном составе насаждений преобладают вяз приземистый и ясень пенсильванский, составляющие 77 \% от общего числа деревьев. При этом наилучшим состоянием отличаются тополь пирамидальный и робиния ложноакациевая, наихудшим - вязы малый и приземистый, шелковица черная, а также ясень пенсильванский и клен американский.
\end{abstract}

Аннотация. В работе рассмотрены методика и результаты оценки видового разнообразия и фактического
} 


\section{ЭКОЛОГИЯ И ПРИРОДОПОЛЬЗОВАНИЕ}

В целом большая часть деревьев, согласно полученным данным, характеризуется категориями состояния «ослабленные» (43\% от общего количества) и «сильно ослабленные» (40 \% от общего количества). Это свидетельствует о наличии долговременных техногенных нагрузок и несвоевременном уходе за состоянием насаждений в совокупности с неблагоприятными климатическими условиями для произрастания древесных пород. В результате санитарнозащитная зона теряет свои защитные свойства, что приводит к усилению уровня негативного воздействия АО ВМК «Красный октябрь» на близлежащую территорию, в т. ч. селитебную зону.

Ключевые слова: санитарно-защитная зона, жизненное состояние насаждений, металлургический комплекс, экологический мониторинг.

Современное антропогенное воздействие на окружающую природную среду затрагивает все ее компоненты: атмосферный воздух, поверхностные и подземные воды, почвенный и растительный покров и т. д. В частности, негативное воздействие на растительность заключается, в осаждении из атмосферы (включая поступление с осадками) различных загрязняющих веществ, в т. ч. соединений тяжелых металлов (ТМ). Даже с учетом того, что большинство ТМ являются необходимыми микроэлементами для нормальной жизнедеятельности растений (например, цинк, медь, марганец, молибден), избыточное их поступление с последующим депонированием в тканях может привести к замедлению роста и развития, изменению цвета и увяданию листьев, недоразвитости корневой системы и даже гибели. Изменение жизненного состояния в совокупности с высокими концентрациями тяжелых металлов в различных органах древесной растительности является одним из признаков антропогенной нарушенности окружающей природной среды. Для городских территорий, в связи с комплексным воздействием большого количества разного вида источников (таких как промышленные предприятия, автомобильный и железнодорожный транспорт, селитебные зоны и др.) проблема загрязнения растительного покрова, как одной из основных депонирующих сред, особенно актуальна $[14,15]$.

Цель исследования - определение состояния древесных насаждений санитарно-защитной зоны (далее - С33) АО ВМК «Красный октябрь» на основе данных, полученных методом геоботанических описаний путем определения жизненного состояния пород.

Методы исследования. В качестве исследуемого объекта была выбрана С33 AО ВМК «Красный Октябрь» г. Волгограда. Данное предприятие, на текущий момент, является одним из крупнейших производителей качественного металлопроката специальных марок стали для предприятий автомобилестроения и авиационной промышленности, нефтяного, химического и энергетического машиностроения, нефтегазодобывающей промышленности в РФ [8].

$\mathrm{AO}$ B,M,К «Красный октябрь» - предприятие с неполным металлургическим циклом, т.е. его технологический передел начинается с выплавки стали, а не с добычи руды или выплавки чугуна. В соответствии с СанПиН 2.2.1/ 2.1.1.1200-03 [6, 7] относится к предприятиям II класса опасности, а размер его санитарнозащитной зоны составляет 500 м (раздел 4.1.2, класс II, п. 3 «Производство стали мартеновским, электроплавильным и конверторным способами с цехами по переработке отходов (размол томасшлака и пр.) при выпуске основной продукции в количестве до 1 млн. т/год»).

Особенности производственного цикла в совокупности с устаревшим оборудованием делают его крупным источником разнопланового воздействия на компоненты окружающей среды, в том числе загрязнения атмосферы и почвенной среды тяжелыми металлами. Расположение границ фактической и нормативной C33 предприятия указано на рисунке 1.

Геоботаническое описание защитных насаждений проводилось в III декаде сентября II декаде октября 2017 г., то есть в конце вегетационного периода [2], на предварительно выбранных 7 геоботанических площадках, равномерно расположенных на территории С33.

В основе анализа экологического состояния зеленых насаждений лежит метод определения количественного, видового и возрастного состава и оценка жизненного состояния (ОЖС) древостоя [3, 5, 9].

Проведение измерений. Определение экологического состояния зеленых насаждений специального назначения, в случаях, когда количество деревьев на исследуемой тер- 
ритории превышает 300 штук, осуществляется в несколько этапов $[1,10,13]$ :

1) Приблизительная оценка общего количества деревьев на исследуемой территории;

2) Установление количества и мест расположения геоботанических (пробных) площадок, их конфигурации;

3) Натурные исследования на выбранных площадках;

4) Анализ полученной информации и составление общей характеристики насаждений на всем объекте исследования.

Поскольку территория С33 ВМК «Красный октябрь» относится к вышеуказанным случаям, то для ее исследования, учитывая рельеф местности, особенности расположения исследуемых санитарно-защитных насаждений и их конфигурацию, были выделены 7 пло-

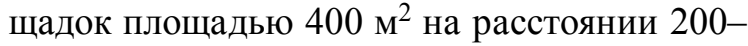
300 м друг от друга. Схематическое расположение площадок показано на рисунке 2 .

В ходе натурных исследований на каждую пробную площадку составлялось геоботаническое описание на специальном бланке, где отмечались: характеристика месторасположения, расстояние от дороги, положение относительно дороги, координаты, дата описания, количество деревьев на площадке, по-

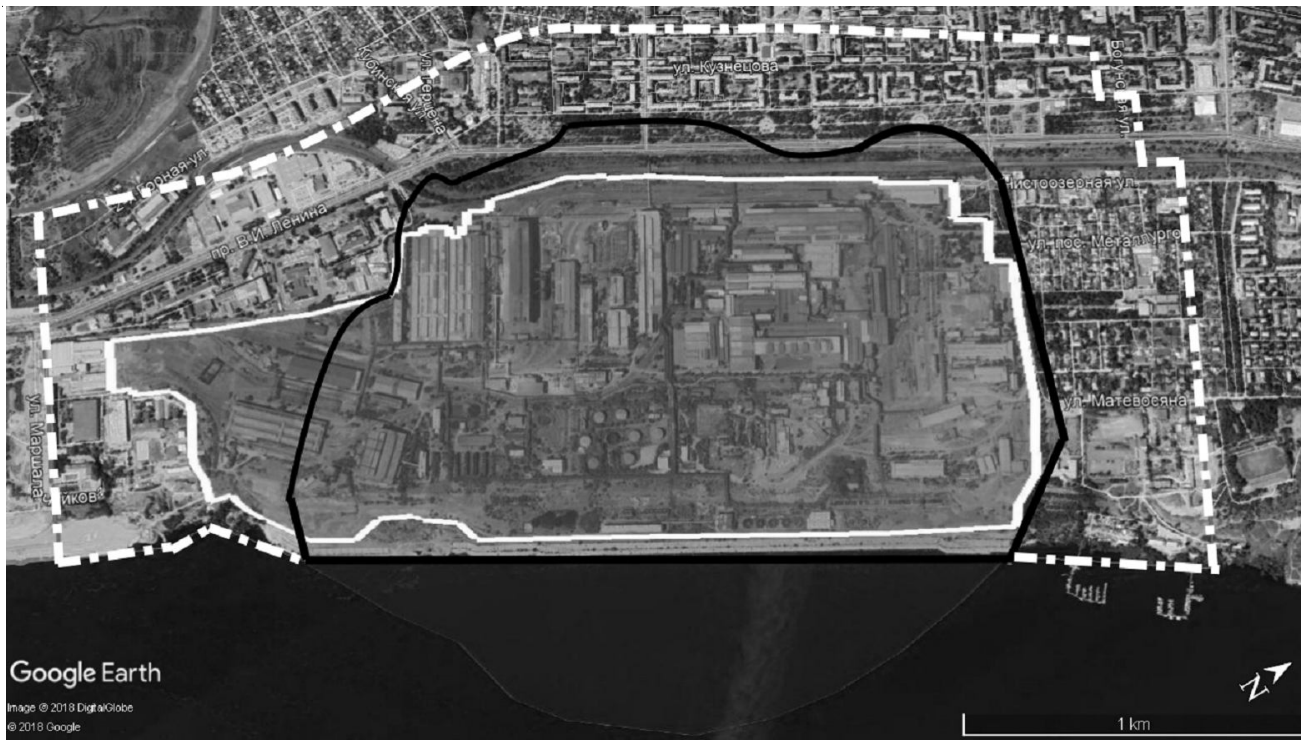

Рис. 1. Расположение границ фактической и нормативной С33 АО ВМК «Красный октябрь» (составлено автором):

Сплошной белой линией обозначена граница АО ВМК «Красный октябрь»; сплошной черной - граница фактической С33; прерывистой белой - нормативная С33

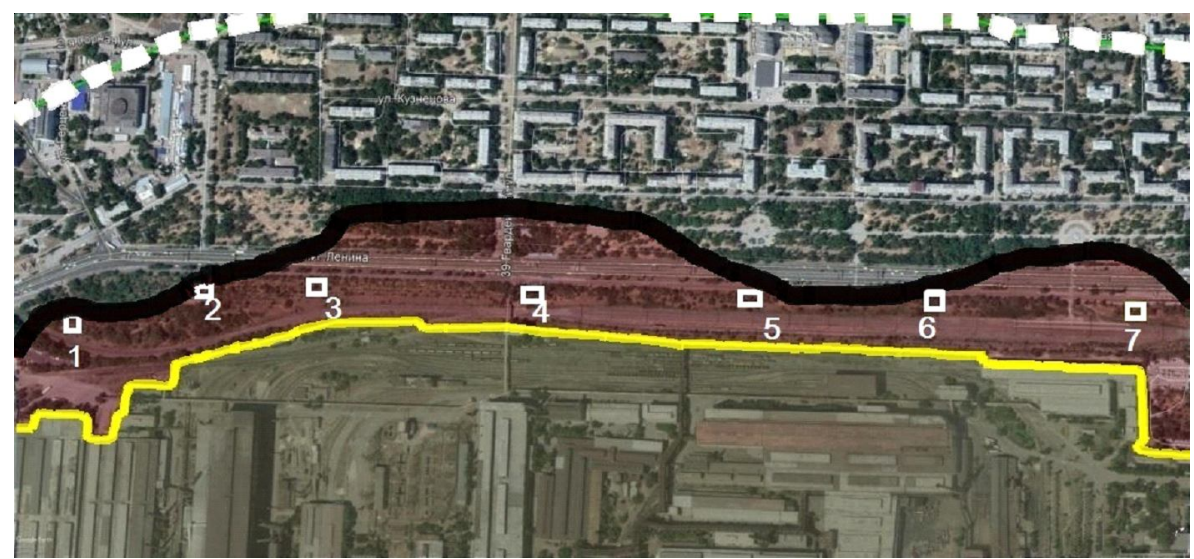

Рис. 2. Расположение геоботанических площадок вдоль западной границы промышленной площадки АО ВМК «Красный октябрь» в пределах фактической С33 (составлено автором):

1-7 - номера геоботанических площадок 


\section{ЭКОЛОГИЯ И ПРИРОДОПОЛЬЗОВАНИЕ}

родный состав, высота деревьев, категория состояния. При перечете деревьев указывались: порода, диаметр, категория состояния, повреждение вредителями, поражение болезнями и другими негативными (в том числе, антропогенными) факторами среды $[1,4,12]$.

В учетной карточке пробной площадки указывались следующие параметры и показатели деревьев:

- вид древесного растения;

- диаметр ствола (см) на высоте 1,3 м;

- высота дерева (м);

- возрастная группа дерева (класс возраста 1-5): до 15 лет, 15-25 лет, 25-45 лет, 45-60 лет и старше 60 лет;

- категория состояния дерева, определяемая на основе признаков, указанных в таблице 1.
Результаты и обсуждение. Полученные в результате натурных исследований данные о видовом составе насаждений отражены на рисунке 3. Согласно этим данным можно отметить, что преобладающими породами на территории С33 АО ВМК «Красный Октябрь» являются вяз приземистый (57\% от общего числа деревьев) и ясень пенсильванский $(25 \%)$.

Результаты исследования жизненного состояния древесного насаждений представлены в таблице 2, распределение деревьев по категориям отражены на рисунке 4.

Следует учитывать, что единичные экземпляры поврежденных, ослабленных или усыхающих деревьев являются нормой для лесных насаждений. Даже в естественных

Категории состояния деревьев [1]

Таблииа 1

\begin{tabular}{|c|c|c|}
\hline Балл & $\begin{array}{c}\text { Категории состоя- } \\
\text { ния деревьев }\end{array}$ & Признаки деревьев разных категорий состояния \\
\hline 1 & $\begin{array}{l}\text { Без признаков } \\
\text { ослабления }\end{array}$ & $\begin{array}{l}\text { Листва или хвоя зеленые нормальных размеров, крона густая нормальной формы и раз- } \\
\text { вития, повреждения вредителями и поражение болезнями единичны или отсутствуют }\end{array}$ \\
\hline 2 & Ослабленные & $\begin{array}{l}\text { Листва или хвоя часто светлее обычного, в кроне менее } 25 \% \text { сухих ветвей. Возможны } \\
\text { признаки местного повреждения ствола механические повреждения }\end{array}$ \\
\hline 3 & $\begin{array}{l}\text { Сильно ослаб- } \\
\text { ленные }\end{array}$ & $\begin{array}{l}\text { Листва мельче или светлее обычной крона изрежена, сухих ветвей от } 25 \text { до 50\%. Часто } \\
\text { имеются признаки повреждения болезнями и вредителями ствола, ветвей, хвои и лист- } \\
\text { вы, в том числе попытки или местные поселения стволовых вредителей }\end{array}$ \\
\hline 4 & Усыхающие & $\begin{array}{l}\text { Листва мельче, светлее или желтее обычной, хвоя серая, желтоватая или желто-зеленая, } \\
\text { часто преждевременно опадает или усыхает, крона сильно изрежена, в кроне более } 50 \% \\
\text { сухих ветвей,. На стволе и ветвях часто имеются признаки заселения стволовыми вреди- } \\
\text { телями }\end{array}$ \\
\hline 5 & $\begin{array}{l}\text { Сухостой теку- } \\
\text { щего года }\end{array}$ & $\begin{array}{l}\text { Листва усохла, увяла или преждевременно опала, хвоя серая, желтая или бурая, крона } \\
\text { усохла, но мелкие веточки и кора сохранились. На стволе, ветвях и корневых лапах час- } \\
\text { то признаки заселения стволовыми вредителями или их вылетные отверстия }\end{array}$ \\
\hline 6 & $\begin{array}{l}\text { Сухостой про- } \\
\text { шлых лет }\end{array}$ & $\begin{array}{l}\text { Листва или хвоя осыпались или сохранились лишь частично, мелкие веточки и часть } \\
\text { ветвей опали, кора разрушена или опала на большей части ствола. На стволе и ветвях } \\
\text { имеются вылетные отверстия насекомых, под корой - обильная буровая мука и грибница } \\
\text { дереворазрушающих грибов }\end{array}$ \\
\hline
\end{tabular}

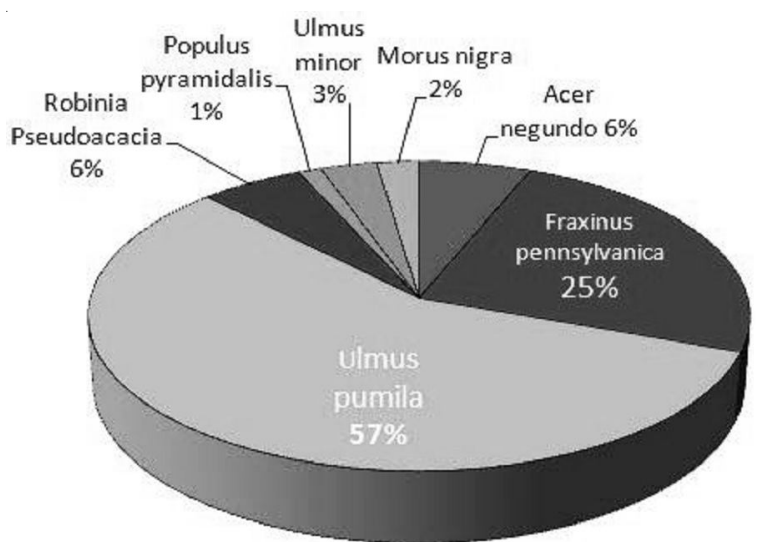

Рис. 3. Видовой состав защитных насаждений на территории СЗ3 АО ВМК «Красный Октябрь» (составлено автором) 


\section{Количество древесных насаждений по категориям состояния на территории} СЗ3 АО ВМК «Красный Октябрь» (составлено автором)

\begin{tabular}{|c|c|c|c|c|c|c|c|c|}
\hline \multirow{2}{*}{$\begin{array}{c}\text { Категория } \\
\text { состояния }\end{array}$} & \multicolumn{7}{|c|}{ Геоботанические площадки } & \multirow{2}{*}{ Всего } \\
\hline 1 & 2 & 1 & 2 & 1 & 3 & 8 & - & 17 \\
\hline 2 & 13 & 17 & 24 & 13 & 23 & 30 & 50 & 170 \\
\hline 3 & 35 & 13 & 32 & 13 & 25 & 31 & 10 & 159 \\
\hline 4 & 8 & 2 & 6 & 5 & 5 & 4 & 6 & 36 \\
\hline 5 & 3 & - & 4 & - & 1 & - & 1 & 9 \\
\hline 6 & 1 & - & 2 & - & 1 & 1 & 1 & 6 \\
\hline
\end{tabular}

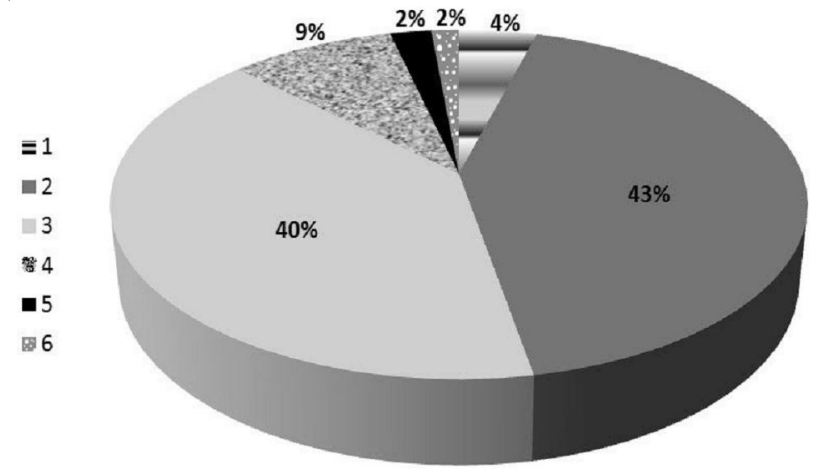

Рис. 4. Распределение общего состава насаждений в пределах фактической С33 АО ВМК «Красный октябрь» по категориям жизненного состояния (составлено автором):

1-6 - категории состояния насаждений (1 - без признаков ослабления; 2 - ослабленные; 3 - сильно ослабленные; 4 - усыхающие; 5 - сухостой текущего года; 6 - сухостой прошлых лет)

широколиственных лесах до $20 \%$ деревьев имеют признаки поражения вредителями и соответствуют категории состояния «ослабленные», что считается нормальным явлением. Однако превышение этого показателя свидетельствует об угнетенном состоянии лесного биоценоза [11].

Полученные данные говорят о том, что большая часть деревьев характеризуется категориями состояния «ослабленные» (2 балла) и «сильно ослабленные» (3 балла). Наихудшими по общему состоянию являются площадки №1 и №3, расположенные к западу от действующих сталеплавильных цехов предприятия. В соответствии с преобладающей в данном районе розой ветров, они находятся в области потенциального риска загрязнения выбросами.

Заключение. Таким образом, результаты оценки жизненного состояния зеленых насаждений санитарно-защитной зоны АО ВМК «Красный октябрь» свидетельствуют о наличии долговременного и разнопланового негативного антропогенного воздействия, а также о несвоевременном и неполноценном уходе за древесными насаждениями. Из-за этого сильно ослабевают защитные свойства С 33 , что приводит к усилению техногенной нагрузки металлургического комплекса на близлежащие территории, в т. ч. селитебную зону. Учитывая опасность данного производства, помимо ухудшения качества городской среды, создается риск здоровью населения.

\section{ПРИМЕЧАНИЕ}

1 Работа выполнена при финансировании «Пакета социальной поддержки на 2017 год молодых ученых ВолГУ» (приказ №01-07.1-503 от 04.07.2017 г.).

\section{СПИСОК ЛИТЕРАТУРЫ}

1. Боголюбов, А. С. Методы геоботанических исследований: методическое пособие / А. С. Боголюбов. - М. : Экосистема, 1996. - 21 с.

2. Климат Волгограда // Погода и климат от 17.09.2017. - Режим доступа: http://www.pogodaiklimat. ru/climate/34560.htm. 


\section{ЭКОЛОГИЯ И ПРИРОДОПОЛЬЗОВАНИЕ}

3. Манджиева, С. С. Экологическое состояние почв и растений природно-техногенной сферы: монография / С. С. Манджиева, Т. М. Минкина // Южный федеральный университет. - 2014. - 264 с.

4. Методика оценки экологического состояния зеленых насаждений общего пользования Санкт-Петербурга: распоряжение Комитета по природо-пользованию, охране окружающей среды и обеспечению экологической без-опасности Правительства СПб от 30 августа 2007 г. № 90-р // Законодательное Собрание СПб. - 2007. - 9 с.

5. Методические рекомендации по проведению полевых и лабораторных исследований почв и растений при контроле загрязнения окружающей среды металлами / Институт экспериментальной метеорологии, МГУ им. М. В. Ломоносова; Под ред. Н. Г. Зырина, С. Г. Малахова. - М.: Гидрометеоиздат Моск. отд-ние, 1981. - 109 с.

6. Объект 18-0134-000164-П АО «ВМК «Красный октябрь» // ПТО УОНВОС: Открытый реестр объектов НВОС от 14.12.2017 - Режим доступа: https://onv.fsrpn.ru/\#/public/registry/18-0134-000164$\% \mathrm{D} 0 \% 9 \mathrm{~F}$.

7. Постановление Главного государственного санитарного врача РФ от 25.09.2007 N 74 (ред. от 25.04.2014) «О введении в действие новой редакции санитарно-эпидемиологических правил и нормативов СанПиН 2.2.1/2.1.1.1200-03 «Санитарно-защитные зоны и санитарная классификация предприятий, сооружений и иных объектов» (Зарегистрировано в Минюсте России 25.01.2008 N 10995) // Консультант Плюс: информ. система. - 2017. - 16 сентября.

8. Справка о предприятии ВМК «Красный октябрь» // ВМК «Красный октябрь» от 14.10.2017. Режим доступа: http://www.vmzko.ru/spravka.html.

9. Avery, T. E. Forest Measurements / T. E. Avery, H. E. Burkhart. - McGraw-Hill Publishing Co., N.Y. 1983. - $329 \mathrm{pp}$.

10. Barrett, T. M. Inventory / T. M. Barrett, O. Eckmuller, J. S. Fried, H. G. Lund, M. Kohl, T. Nuutinen // Chapter in Encyclopedia of forest sciences. - Elsevier Ltd., Oxford, UK - 2004. - Volume 1. - P. 403-433.

11. Forest Health Fundamentals // Florida Department of Agriculture and Consumer Services 12.12.2017. URL: https://www.freshfromflorida.com/ Divisions-Offices/Florida-Forest-Service/Our-Forests/ Forest-Health/Forest-Health-Fundamen-tals.

12. Forest inventory // Florida Forest Stewardship 12.12.2017. URL: http://www.sfrc.ufl.edu/ extension/florida_forestry_information/forest_ management/inventory.html.

13. Forest inventory // Food and Agriculture Organization of the United Nations 13.12.2017. URL: http://www.fao.org/sustainable-forest-management/ toolbox/modules/forest-inventory/basic-knowledge/ en/?type $=111$
14. Diatta, J.B. Assessment of heavy metal contamination of soils impacted by a Zinc smelter activity / J.B. Diatta, E. Chudzinska, S. Wirth // J. Elementol. - 2008. - 13(1). - P. 5-16.

15. Medycska-Juraszek, A. Lead. Mercury and Cadmium in Forest Soils Impacted by Copper Industry in South-West Poland / A. Medycska-Juraszek, C. Kabaia // International Conference on Heavy Metals in the Environment. - 2010. - P. 793-797.

\section{REFERENCES}

1. Bogoljubov A.S. Metody geobotanicheskih issledovanij: metodicheskoe posobie. M., Jekosistema, 1996, 21s.

2. Klimat Volgograda // Pogoda i klimat. URL http://www.pogodaiklimat.ru/climate/34560.htm (accessed September 17, 2017)

3. Mandzhieva S.S., Minkina T.M. Jekologicheskoe sostojanie pochv i rastenij prirodnotehnogennoj sfery: monografija , Juzhnyj federal'nyj universitet, 2014, $264 \mathrm{~s}$.

4. Metodika ocenki jekologicheskogo sostojanija zelenyh nasazhdenij ob-shhego pol'zovanija Sankt-Peterburga: rasporjazhenie Komiteta po prirodo-pol'zovaniju, ohrane okruzhajushhej sredy i obespecheniju jekologicheskoj bez-opasnosti Pravitel'stva SPb ot 30 avgusta 2007 g. № 90-r, Zakonodatel'noe Sobranie SPb , 2007, 9 s.

5. Metodicheskie rekomendacii po provedeniju polevyh i laboratornyh issledovanij pochv $\mathrm{i}$ rastenij pri kontrole zagrjaznenija okruzhajushhej sredy metallami; Pod red. N. G. Zyrina, S. G. Malahova. M., Gidrometeoizdat Mosk. otd-nie, 1981, 109 s.

6. Ob\#ekt 18-0134-000164-PAO «VMK «Krasnyj oktjabr'», PTO UONVOS: Otkrytyj reestr ob\#ektov NVOS, URL: https://onv.fsrpn.ru/\#/public/registry/180134-000164-\%D0\%9F (accessed December 14, 2017)

7. Postanovlenie Glavnogo gosudarstvennogo sanitarnogo vracha RF ot 25.09.2007 N 74 (red. ot 25.04.2014). «O vvedenii $v$ dejstvie novoj redakcii sanitarno-jepidemiologicheskih pravil i normativov SanPiN 2.2.1/2.1.1.1200-03 «Sanitarno-zashhitnye zony i sanitarnaja klassifikacija predprijatij, sooruzhenij i inyh ob\#ektov" (Zaregistrirovano v Minjuste Rossii 25.01.2008 N 10995), Konsul'tant Pljus: inform. Sistema, 2017, 16 sentjabrja.

8. Spravka o predprijatii VMK «Krasnyj oktjabr'»,VMK «Krasnyj oktjabr'», URL: http:// www.vmzko.ru/spravka.html (accessed October 14, 2017).

9. AveryT.E., Burkhart H.E. Forest Measurements. N.Y., McGraw-Hill Publishing Co, 1983. 329 p.

10. Barrett T.M., Eckmuller O., Fried J.S., Lund H.G., Kohl M., Nuutinen T. Inventory, Chapter in Encyclopedia of forest sciences. UK, Oxford, Elsevier Ltd. 2004. Volume 1.pp. 403-433. 
11. Forest Health Fundamentals. Florida Department of Agriculture and Consumer Services. URL: https://www.freshfromflorida.com/DivisionsOffices/Florida-Forest-Service/Our-Forests/ForestHealth/Forest-Health-Fundamentals (accessed December 12, 2017).

12. Forest inventory. Florida Forest Stewardship. URL: http://www.sfrc.ufl.edu/extension/ florida forestry information/forest management/ inventory.html (accessed December 12, 2017).

13. Forest inventory // Food and Agriculture Organization of the United Nations URL: http:// www.fao.org/sustainable-forest-management/toolbox/ modules/ forest-inventory/basic-knowledge/en/ ?type=111 (accessed December 13, 2017).

14. Diatta, J.B., Chudzinska E., Wirth S. Assessment of heavy metal contamination of soils impacted by a Zinc smelter activity, J. Elementol., 2008, 13(1), pp. 5-16.

15. Medycska-Juraszek, A., Kabaia C. Lead, Mercury and Cadmium in Forest Soils Impacted by Copper Industry in South-West Poland, International Conference on Heavy Metals in the Environment., 2010, pp. 793-797.

\section{Information about the Authors}

Anna A. Tikhonova, Postgraduate Student, Department of Ecology and Nature Management, Volgograd State University, Prosp. Universitetsky, 100, 400062 Volgograd, Russian Federation, tihonova@volsu.ru.

Dmitriy A. Shkolnykh, Graduate Student, Department of Ecology and Nature Management, Volgograd State University, Prosp. Universitetsky, 100, 400062 Volgograd, Russian Federation, dimych4265@yandex.ru.

\section{Информация об авторах}

Анна Афанасьевна Тихонова, аспирант кафедры экологии и природопользования, Волгоградский государственный университет, просп. Университетский, 100, 400062 г. Волгоград, Российская Федерация, tihonova@volsu.ru.

Дмитрий Александрович Школьных, магистрант кафедры экологии и природопользования, Волгоградский государственный университет, просп. Университетский, 100, 400062 г. Волгоград, Российская Федерация, dimych4265@yandex.ru. 